\title{
The renewal of licensing system for nuclear reactors in Indonesia
}

\author{
Amil Mardha \\ Nuclear Energy Regulatory Agency (BAPETEN), Jl. Gajah Mada No. 8, \\ Jakarta Pusat 10120, Indonesia \\ Fax.+62-21-6302547 E-mail: a.mardha@bapeten.go.id
}

\begin{abstract}
This paper describes the renewal of the licensing system for nuclear reactors in Indonesia stipulated in the new legislation and regulations. The new Act, Number 10 Year 1997 on Nuclear Energy, provides for licensing by the regulatory body of personnel and installations. The construction and operation of nuclear reactors and other nuclear installations, as well as the decommissioning of nuclear reactors, will be subjected to licensing. The requirements and procedures of the licence grant process are briefly defined in the new Government Regulation of the Republic of Indonesia Number 43 Year 2006 on Licensing of Nuclear Reactors as the implementation of the Act.
\end{abstract}

Keywords: act; Indonesia; licence; licensing of nuclear reactors; permit.

Reference to this paper should be made as follows: Mardha, A. (2008) 'The renewal of licensing system for nuclear reactors in Indonesia', Int. J. Nuclear Law, Vol. 2, No. 1, pp.66-77.

\begin{abstract}
Biographical notes: Amil Mardha graduated in Physics (BSc) with specialisation in nuclear instrumentation in the University of Indonesia, Jakarta, Indonesia, in 1986. He received a Master of Engineering in nuclear engineering in Japan in 1993. From September 1986 to March 1986 he worked in The Center of Nuclear Reactor Bandung National Nuclear Energy Agency (BATAN). From April 1986 to August 1999, he was a researcher of reactor physics at The Center of Multipurpose Nuclear Reactor (MPR-30), Serpong National Nuclear Energy Agency (BATAN). Since August 1999 he has been working at the Nuclear Energy Regulatory Agency (BAPETEN), where he is currently the Head of Sub Directorate of Regulating Power Reactor (NPP) and is responsible for establishing the regulation, codes, guides and standards of the construction and operation of the first nuclear power plant in Indonesia.
\end{abstract}

\section{Introduction}

In anticipation of the possible construction of the country's first nuclear power plant in the near future, the Government of Indonesia decided to replace the existing nuclear law Number 31 Year 1964 on Basic Provision of Atomic Energy with new legislation, i.e. Act Number 10 Year 1997 on Nuclear Energy ${ }^{1}$. This Act on Nuclear Energy stipulates an independent separation between an executing body, namely BATAN, responsible for promoting nuclear activities and a regulatory body, namely BAPETEN, responsible for controlling the use of nuclear energy. Based on this act, BAPETEN establishes regulations 
and issues licences and performs inspections. The Act Number 10/1997 provides for licensing by the regulatory body of personnel and installations. The construction and operation of nuclear reactors and other nuclear installations, as well as the decommissioning of nuclear reactors shall be subjected to licensing. The requirement and procedure of the licensing mechanism is stipulated in the new Government Regulation of Republic Indonesia (GR-RI) Number 43/2006 on Licensing of Nuclear Reactors as implementation of the Act. $^{2}$

According to implementation of the old Act Number 31/1964 namely, the Decree of Director General of BATAN Number 54 year 1982 on construction and operation of nuclear reactor stipulates that licences are issued by BATAN. These licences are siting, construction, operation and decommissioning licences. However, in the implemantation of Act Number 10/1997, the GR-RI Number 43/2006 on Licensing of Nuclear Reactors stipulates that the two types of licences are five-step licences and three-step licences. Five-step licences include site permits, construction permits, commissioning licences, operation licences and decommissioning permits. Three-step licences consists of site permit, combined operation licensing (COL) and decommissioning permits. The COL is a combination of construction permit, commissioning licence and operation licence.

\section{Nuclear legislation of nuclear activity}

Nuclear legislation in Indonesia was initiated by Act Number 31 Year 1964 on Basic Provision of Atomic Energy. This Act stipulated on September 26, 1964 and was inserted in the State Gazette of the Republic of Indonesia Year 1964, Number 124, Supplement to the State Gazette Number 2722. Based on this act, the National Atomic Energy Agency (BATAN - Badan Tenaga Atom Nasional) was established, with two simultaneous functions, promotion and control of nuclear energy in Indonesia. The following functions have been mentioned in Article 3 paragraph (1):

"the President set up a National Atomic Energy Agency which executes, regulates and controls research and use of atomic energy in Indonesia for the safety, health and welfare of the Indonesian people."

While the following functions are mentioned clearly in Article 6:

"The National Atomic Energy Agency is the supreme executive and control body in the use of atomic energy in Indonesia."

Later, when Indonesia considered seriously the existence of nuclear power plants since the 1980s, there was a need to amend the act. On 10th April 1997, Act No. 31/1964 was repealed by Act Number 10 Year 1997 on Nuclear Energy.

In the new act, the two functions mentioned above are separated and are now held by the National Nuclear Energy Agency (BATAN - Badan Tenaga Nuklir Nasional) and the Nuclear Energy Regulatory Agency (BAPETEN - Badan Pengawas Tenaga Nuklir), respectively. The separate functions are stated in Article 3 and Article 4 of Act Number 10 Year 1997. Article 3 regulates the promotional body (BATAN) and Article 4 regulates the regulatory body (BAPETEN).

Article 3 contains two paragraphs: 
1 The government establishes an executing body, under and directly responsible to the president. The executing body shall have the task of executing the use of nuclear energy.

2 To accomplish the task under clause (1), the executing body conducts research and development, general surveys, explorations and exploitations of nuclear ore, raw material production for manufacturing and fabrication of nuclear fuel, production of radioisotopes for research and development and radioactive waste management.

Article 4 contains two paragraphs:

1 The government establishes a regulatory body, under and directly responsible to the president. The regulatory body shall have the task of controlling any activity using nuclear energy.

2 To accomplish the task under paragraph (1), the regulatory body establishes regulations and conducts licensing processes and inspections.

As stipulated in Article 17 para (2) Act Number 10 Year 1997 on Nuclear Energy:

"the construction and operation of nuclear reactors and other nuclear installations as well as the decommissioning of nuclear reactors shall be subjected for licensing."

Next para (3) stipulates that:

"The requirements and procedures of licensing under paragraph (1) and paragraph (2) will be further stipulated by government regulations."

As implementation of Article 17 para (3), the GR-RI on licensing of nuclear reactor was established on 15 December 2006 with number 43. The licensing also holds for employees who operate a nuclear reactor and any special employees in other nuclear installations and in the installations that use ionising radiation sources as stipulated in Article 19 para (1):

"Any employee who operates a nuclear reactor and any special employee in other nuclear installations and in the installations that use ionising radiation sources shall possess a licence."

\section{Nuclear reactor licensing}

To carry out nuclear reactor projects successfully, safety should be assured throughout all stages of the project, namely site selection, design, manufacturing, construction, operation, maintenance and decommissioning. Securing nuclear safety is a prerequisite to the development and utilisation of nuclear energy and all workers engaged in nuclear activities should adhere to the principle of "priority to safety".

Performed controls are from site selection, construction and operation to decommissioning. One form of nuclear safety control activity is performed through licensing. Each construction, operation and decommissioning of nuclear reactor shall be subjected for licensing as enacted in Article 17 paragraph (2) of the Act Number 10 year 1997 on Nuclear Energy. Therefore, a regulation regarding the licensing system shall be set up that accommodates licensing requirements and procedures for nuclear reactor 
construction, operation and decommissioning activities through various assessment and review processes on each stage. In the construction, operation and decommissioning of nuclear reactors, the nuclear installation operator shall obey the licensing requirements and procedures of nuclear reactors, namely the technical requirements on each licensing stage and also administrative requirements related to the identity/institute of the applicant and requirements or other licensing set by other competent authorities/institutes.

Before the licence to build a nuclear reactor is given, the licence applicant must previously have completed and owned a licence or fulfil other requirements from the related authorised institute for spacing layout, right of use of the ground for the site, the building construction, the manpower, the electric power, etc. After the requirements are met by the licence applicant then BAPETEN can continue the licence grant process for the construction, operation and decommissioning of the nuclear reactor by performing an assessment for each licensing stage.

All the licensing processes shall be shown as a continuing process, started from site evaluation activity to the stage of nuclear reactor decommissioning. The licence that has been issued or applicable for a certain activity has a definition that can be considered as approval to perform the cited activity.

\subsection{Assessment and types of licence}

Assessment on the licence application document of each licensing stage must be performed by BAPETEN. The assessment includes site evaluation, design and construction, commissioning, operation and decommissioning. BAPETEN performs the assessment on licence applications with its full set of documents in a certain period of time. Each assessment has a certain time period in accordance with the type of licence. Procedures and review time period will be further governed by the Chairman Decree of BAPETEN.

Types of licence for construction, operation and decommissioning of nuclear reactors issued by BAPETEN are five-step licences and three-step licences. Five-step licences can be gradually obtained in the form of:

- site permit

- construction permit

- commissioning licence

- operation licence

- decommissioning permit.

Another selection process is three-step licences, which consists of site permit, combined operation licence and decommissioning permit. This type of three-step licence can be obtained for a reactor with a modular design that has gained a design certificate (nuclear reactor standard) from the regulatory body of the vendor country or a reactor that has been developed and approved abroad. BAPETEN may issue a combined operation licence after the applicant has obtained a site permit. The definition of a combined operation licence is construction permit, commissioning licence and operation licence with the requirements combined and simplified to make it time- and cost-efficient. Those licences mentioned above can be granted through an assessment performed by the Chairman of BAPETEN. 
In the government regulation on licensing of nuclear reactors, the construction, operation and decommissioning of nuclear reactors included power reactors and non-power reactors operated for commercial and non-commercial purposes. A nuclear power reactor with commercial purpose established in Indonesia is a reactor that is designed based on proven technology. The meaning of proven technology is technology used in nuclear power design which is already proven to be safe through reactor operation experience of at least three years with a capacity factor minimum average of $75 \%$.

\subsection{Requirements and the licence grant process}

\subsubsection{Site permit}

Before submitting the site permit application, the applicant must perform a site evaluation activity. This evaluation activity is performed after completing the requirements of the site evaluation in the form of a site evaluation programme and quality assurance of the site evaluation programme.

The site permit is effective from the date of issuance until the release-of-site statement for unrestricted use is issued by the Chairman of BAPETEN. In issuing the site permit there are several activities that must have been previously performed by the permit applicant and the nuclear installation operator must arrange and submit the Quality Assurance of Site Evaluation Programme to the BAPETEN for approval. After this quality assurance programme has been approved, the applicant may start to perform the site evaluation. After the site evaluation activities have been completed, the applicant may obtain a site permit by fulfilling the application of administrative requirement and completing the document of technical requirements containing:

- Result report of site evaluation, at least to consist of:

- $\quad$ structure of executive organisation

- documentation and reporting

- data evaluation and analysis regarding:

- impacts of external events within the site and its vicinity that are caused by natural events including geological, seismological and meteorological events as well as events that are caused by human activities against nuclear reactor safety coming from chemical installation, toxin release, inflammable gas and air crashes

- $\quad$ site and its environment characteristics that can influence nuclear installation and radioactive material released from nuclear reactor to humans and the environment

- $\quad$ population demography and other characteristics of the site related to the risk evaluation against public members and the feasibility of the implementation plan for emergency preparedness.

- Main data of nuclear reactor that will be established, at least consists of:

- the number, type and thermal power level of nuclear reactor that will be established 
- the position of the nuclear reactor and its facilities within the site

- the estimation of maximum radiology level and thermal effluent that will be produced by each nuclear reactor and its facilities

- the type of cooling system, the position of the water intake and the effluent release that are related to each of the facilities.

- Preliminary design information questionaire (PDIQ) - the preliminary design information questionnaire is a nuclear material safeguards questionaire that generally describes facilities' arrangement within the site.

- Recorded implementation of quality assurance programme of site evaluation.

\subsubsection{Construction permit}

After obtaining a site permit, a construction permit application may be submitted by the nuclear installation operator (site permit holder) to the BAPETEN before the construction is started by attaching the following documents:

- Preliminary safety analysis report - this report shall at least describe:

- installation lay out, site characteristics, design characteristics of structure, system, component and instruments

- nuclear reactor core, cooling system and other related systems

- reactor safety system, instrumentation and control system

- radioactive waste management and radiation protection

- $\quad$ safety analysis

- preliminary operation limitation and conditions

- quality assurance programme

- decommissioning plan

- nuclear emergency plan.

- Detailed design of the nuclear reactor.

- Quality assurance programme on construction.

- Design information questionaire (DIQ).

- Construction programme.

- The preliminary nuclear security system describing the physical protection programme for the facilities.

- A recommendation from the competent authority on the environmental impact assessment.

- Legal documents of financial ability to ensure the implementation of construction.

- Probabilistic safety analysis report for commercial power reactors. 
This report shall at least contain:

- system, structure and nuclear reactor component identification

- nuclear reactor response analysis

- selection of initiating events that initiates the accidents

- accident sequence propagation

- system and human reliability analysis

- qualitative and quantitative analysis

- core damage frquency probability.

After performing the checking of construction permit application document completeness for one month and document assessment administratively and technically for two years and the application is considered to meet the requirement, the BAPETEN shall issue the construction permit. This construction permit is given to perform activities from the preparation or first foundation casting to the non-nuclear commissioning, namely the installation and testing of a reactor component with its supporting system until the reactor core is ready to be filled with nuclear fuel.

The time period of the construction permit is given as, at longest, five years. If, in this time period, the nuclear installation operator plans to change the design, structure modification, system or component to influence the nuclear reactor safety, the nuclear installation operator shall submit an application to obtain previous approval from the BAPETEN.

The nuclear installation operator is obligated to start performing the construction activities at a maximum of one year from the granting of the construction permit. If the nuclear installation operator does not complete the construction activities within the period of the construction permit then the nuclear installation operator shall submit an extension licence application in a period of (maximum) six months before the construction permit expires by attaching:

- a report of results of the progress of the latest construction activities

- a new construction programme and schedule of activities.

The extension of the construction licence is issued for a maximum of two years every time it is extended.

\subsubsection{Commissioning licence}

Before operating the nuclear reactor, the construction permit holder shall perform the commissioning activity at the commissioning stage. In the commissioning stage, the nuclear installation operator has to perform a testing activity to ensure that the system, structure and/or components installed in the nuclear reactors that are operated by nuclear fuel meet the requirements and design criteria. The applicant may obtain a commissioning licence by fulfilling the application of administrative requirement and complete the document of technical requirements containing: 
- proof that the applicant possesses the licence to use nuclear material

- proof that the reactor operators possess the working permit

- commissioning programme

- construction activities report, including the report on functional testing of the structure, system and components of the nuclear reactor

- as-built technical drawing of nuclear reactor

- safeguards and nuclear security systems

- nuclear emergency preparedness programme

- quality assurance programme on commissioning

- the report on the implementation of environment management and monitoring plan

- legal documents of financial guarantee for nuclear liability

- legal documents of financial guarantee for the implementation of decommissioning activities of the nuclear reactor.

After checking the completeness of the commissioning licence application document for one month and assessing the document administratively and technically for one year, if it is considered to meet the requirement, then BAPETEN shall issue the commissioning licence.

The time period of the commissioning licence is given at a maximum of two years. The nuclear installation operator shall start to perform the commissioning activity at a maximum of six months from the granting of the commissioning licence. If the nuclear installation operator does not complete the commissioning activites within the period of the commissioning licence, the nuclear installation operator shall submit an extension licence, a maximum of six months before the commissioning licence expires by attaching:

- a progress report of commissioning activities

- a new commissioning programme and schedule of activity.

The extension of the commissioning licence is issued for a maximum of one year every time it is extended.

\subsubsection{Operation licence}

An operation licence is not included as a nuclear material utilising licence. Once the commissioning activity is finished and its result fulfill the requirement and design criteria showing that the nuclear reactor can operate normally, safely and securely according to the design and that the applicant possesses the nuclear material utilising licence and the reactor operator possesses the working permit, the commissioning licensee may submit an application to obtain an operation licence.

After checking the completeness of the operation licence for one month and document assessment administratively and technically for two years and if it is considered to meet the requirements, then BAPETEN shall issue the operation licence. An operation licence is given and that means the nuclear installation operator may operate the reactor commercially as a power reactor (nuclear power plant). An operation licence is given for 
a maximum of 40 years. However, if after evaluation the nuclear reactor is suitable to be operated from the point of view of safety and all operation requirements are still fulfilled, this nuclear reactor can be granted an operation extension for a maximum time period of 60 years from the granting of the operation licence. An operation licence extension application shall be submitted, at the latest, five years before the operation licence expires by attaching:

- a final safety analysis report

- the report on operation activities

- the report on ageing assessment.

The applicant may obtain an operation licence by fulfilling the application of administrative requirements and completing the document of technical requirements containing:

- proof that the applicant possesses the licence to utilise nuclear material

- proof that the reactor operators possesses the working permit

- a final safety analysis report which contains the operational conditions and limits and a decommissioning programme

- safeguards facility attachment of nuclear material

- the report on the implementation of the environment management and monitoring plan during commissioning

- a quality assurance programme on operation

- legal documents of financial guarantee to operate nuclear reactors.

\subsubsection{Combined operation licence (COL)}

For a nuclear reactor which is designed/established with a module system (modular design) that has gained a design certificate from the regulatory body of the vendor country and its reactor operates safely and securely in other countries, then the construction permit, commissioning licence and operation licence can be combined all in one, in the form of a COL. The applicant shall submit the COL a maximum of two years from the issue of a site permit.

After performing the assessment, BAPETEN will issue the COL after the permit application with its completeness is considered to fulfill the requirements. BAPETEN will do the assessment during the stages of construction implementation activities and operation of nuclear reactor, for example, nuclear commissioning activity can only be done after BAPETEN assesses and approves the implementation results of construction activity and non nuclear commissioning. The same applies for the normal nuclear reactor operation that can only be done after BAPETEN assesses and approves the results of nuclear commissioning implementation. The assessment of the COL administratively and technically is determined at a maximum of three years and based upon the criteria from the inspection, testing, analysis and acceptance criteria document (ITAAC).

The COL is given for a maximum time period of 45 years and one time extension can be given for a time period of 20 years once the COL reaches its end after having been 
evaluated/assessed that the nuclear reactor is obviously suitable to be further operated from the point of view of safety and all operation requirements are still fulfilled. Application for COL extension shall be submitted at least five years before the COL has expired by attaching:

- a final safety analysis report

- the report on operation activities

- the report on ageing assessment.

The applicant may obtain the COL by fulfilling the application of administrative requirement and complete the document of technical requirements containing:

- a design certificate from the regulatory body of the vendor country

- a safety analysis report

- a quality assurance programme for construction, commissioning and operation activity

- detailed design of the nuclear reactor

- probabilistic safety analysis report for commercial power reactor

- inspection, testing, analysis and acceptance criteria (ITAAC) document

- nuclear emergency preparedness programme

- DIQ

- nuclear safety system

- a recommendation from the competent authority on the environmental impact assessment

- legal documents of financial guarantee for nuclear liability

- legal documents of financial guarantee to assure construction implementation until nuclear reactor decommissioning

- proof that the applicant possesses the licence to utilise nuclear material

- proof that the reactor operators possess the working permit.

In addition to those documents above, the applicant shall submit proof of environment management and environment monitoring implementation after the nuclear commissioning activity is completed and meets the requirements and design criteria.

\subsubsection{Decommissioning permit}

Decommissioning activity is an activity to stop the operation of a nuclear reactor permanently, activities performed include transferring the nuclear fuel from the reactor core, component unloading and nuclear reactor structure, decontamination and final secure. If the nuclear reactor has reached the end of its operation age and/or the nuclear installation operator is not intending to further operate it, the nuclear installation operator shall submit the decommissioning permit application to perform the nuclear reactor decommissioning activity. 
To be able to perform decommissioning activity, the nuclear installation operator shall submit the decommissioning permit application three years before the operation licence or COL has expired. The requirement of this permit application will be assessed administratively and technically by the BAPETEN at a maximum of one year from submission.

When applying for a decommissioning permit, the nuclear installation operator shall make:

- a decommissioning programme

- a decommissioning quality assurance programme submitted to the BAPETEN to be approved.

Nuclear reactor decommissioning can be conducted for the following basic reasons:

- the operation licence and COL has expired and upon the operator's request

- the operator will not be extending the operation licence or COL

- application for an operation licence or COL extention is refused by the Chairman of BAPETEN under nuclear safety and/or security reasons.

A decommissioning permit is to be effective until the release-of-site statement for unrestricted use is issued by the Chairman of BAPETEN. The definition of the release-of-site statement for unrestricted use is a statement that decommissioning activity has been completely performed by the nuclear installation operator and the nuclear reactor site is free from radiation exposure hazards and radioactive substance contamination as a result of research, evaluation and monitoring conducted by the nuclear installation operator. To obtain the release-of-site statement for unrestricted use, the operator shall submit the implementation documentation:

- result on nuclear reactor decommissioning activity

- result on radioactive waste management activity

- result on environment monitoring programme, including the result of radiation exposure testing and radioactive substance contamination inside and outside the site.

\subsubsection{The termination of a licence}

A licence will be terminated on the basis of:

- expiry of the licence

- dissolution of the operating organisation's corporation

- revoking of the licence by the Chairman of BAPETEN

- request applied by the nuclear installation operator.

When the operation licence or COL has terminated as mentioned above, the institution/operator of the nuclear installation which has received the permit should immediately stop the nuclear reactor operation but will still be responsible for the decommissioning implementation, nuclear reactor management, nuclear fuel and radioactive waste management which comply with the applied government regulations. 


\section{Notes}

1 Act Number 10 Year 1997 on Nuclear Energy, BAPETEN, 1997.

2 The Government Regulation of Republic Indonesia Number 43 Year 2006 on Licensing of Nuclear Reactor, BAPETEN, 2006. 